\title{
UMA PERSPECTIVA EMANCIPATÓRIA DA POLÍTICA CRIMINAL
}

\author{
Fabiana de Assis Pinheiro \\ Mestranda em Direito pela UFSC \\ e-mail: fabianaap@superig.com.br
}

RESUMO: O ensaio apresenta uma reflexão sobre o papel da criminologia na consolidação dos direitos da modernidade e propõe novos desafios a esse saber para enfrentamento das dúvidas quanto ao futuro. A perspectiva crítica é apresentada, nesse contexto, como instrumento importante para o futuro da criminologia. Problematiza, no mesmo contexto, o futuro da política criminal, identificando o núcleo da crise no objeto de estudo desse saber. A interdisciplinaridade é apontada como a ferramenta para enfrentamento do problema; a superação da natureza penal da política criminal, como perspectiva. Propõe o redimensionamento do conceito e do seu conteúdo da política criminal como o desafio para atender a um novo objeto de atuação - o tratamento da violência. No tratamento dessa violência, aposta em uma política criminal desenhada pelos princípios constitucionais da Carta Política e com foco de atuação nos direitos fundamentais.

PALAVRAS-CHAVE: Criminologia; Política criminal; Política penal; Violência; Princípios constitucionais; Direitos fundamentais. 


\section{CRIMINOLOGIA: RESGATE DA DÍVIDA}

A partir dos anos quarenta, a criminologia positiva de caráter biológico e psicológico começa a ser questionada pelo modelo etiológico da sociologia do desvio. Este, por sua vez, é criticado pelo paradigma da reação social representado pelo interacionismo simbólico que priorizou, no estudo do desvio e da criminalidade, os mecanismos de etiquetamento institucionais e informais e conseqüentemente, o processo de criminalização primária (criação da lei penal) e secundária (aplicação da lei penal).

Os princípios da igualdade, liberdade e legalidade e outros princípios do direito penal liberal, por meio do qual se traduziu a promessa da modernidade ${ }^{1}$, receberam um novo significado conferido pelo paradigma da reação social. (BARATTA, 2002, p. 32)

Contudo, como nos revela a realidade, os conteúdos teóricos da criminologia e as propostas político-criminais não conseguiram concretizar a promessa da modernidade. Tampouco a criminologia concretizou a promessa de transformação da realidade social, modificando as estruturas sociais, uma vez que estabeleceu um relacionamento parcial e distante com os centros de poder e a consciência social o que provocou a despolitização a respeito do fenômeno criminal.

O futuro da criminologia está vinculado à aproximação da experiência científica com os centros de decisão e, sobretudo, à necessidade de transformar a academia num espaço público de debate para que os cidadãos se envolvam com o debate político-criminal, conscientes de que a elaboração de uma política criminal é responsabilidade de todos nós, uma vez que limita a democracia e o autoritarismo de uma sociedade.

O debate quanto à subsistência da criminologia já foi instaurado.

BARATTA (1999, p. 62) visualiza a fragilidade da criminologia tradicional e da criminologia crítica na definição da sua dimensão comportamental. Entende que a crise atual enfrentada pela criminologia se dá à complexidade do tratamento do problema criminal - que necessita conhecimentos de diversas áreas das disciplinas

1 O direito da modernidade, em vez de superar a violência, acabou por ocultá-la, excluindo do pacto social os sujeitos vulneráveis, tornando juridicamente invisíveis a desigualdade e a violência estrutural.(BARATTA, 1997, p. 64) 
jurídicas, sociológicas, psicológicas e políticas, exigindo-se uma interdisciplinaridade externa para a criminologia.

Para BARATTA (1997, p. 63), "não existe futuro para uma disciplina - a criminologia - que pretenda abarcar toda a dimensão comportamental da questão criminal, isto é, todas as situações problemáticas e de violação dos direitos, toda a violência e todos os conflitos que se referem àquela dimensão".

A proposta do professor busca sobretudo diminuir o abismo criado entre a ciência criminológica, as esferas políticas e a sociedade civil. Circunstância que marcou profundamente a investigação criminologia do século $X X$, inviabilizando a realização do debate acerca do problema criminal e da consolidação dos direitos da modernidade.

A sugestão sustentada no parágrafo anterior pode ser extraída das palavras do professor.

somente um novo discurso que se colocasse transversalmente com respeito à divisão acadêmica do trabalho científico e às disciplinas institucionalizadas seria legítimo, epistemológica e politicamente em relação à chamada dimensão criminal: um discurso que resultasse da participação de atores provenientes de comunidades científicas distintas. Só esse tipo de discurso e esse tipo de sujeito poderiam produzir um saber social orientado ao modelo democrático da interação entre ciências e sociedade, e portanto, orientado às necessidades reais do cidadão. (BARATTA, 1997, p. 67)

\section{CRIMINOLOGIA: NOVOS DESAFIOS}

A questão acerca do futuro da criminologia parece persistir, uma vez que não só a problemática da definição comportamental desta ciência coloca em dúvida seu futuro, mas também a necessidade de mudança, de reflexão a respeito da dimensão do campo da pesquisa criminológica.

$\mathrm{Na}$ verdade, os princípios da modernidade não se realizaram e, no momento, deparam-se com uma nova ideologia que propõe a supressão desses princípios sem que, de fato, tivessem atingido plena vigência. (VIDAURRI, 2001, p.11)

As escolas criminais trabalharam sob bases ideológicas próprias e construíram, sob influência destas, propostas de política criminal. Esta, por sua vez, 
em muitos casos, exerceu papel de ascendência em relação à criminologia, para implantação de ideologias políticas.

As ideologias que inspiraram a modernidade e, conseqüentemente, as escolas criminológicas encontram-se enfraquecidas frente ao fenômeno pósmoderno da globalização e à ideologia neoliberal. Nesta realidade, demanda-se uma discussão em torno do novo campo de estudo da criminologia.

Sugerem alguns pesquisadores a superação da investigação criminológica da repressão e do desvio e o investimento na pesquisa das instâncias formais e informais de controle, priorizando-se o estudo das estratégias utilizadas na sociedade civil, para que as maiorias consintam espontaneamente com as orientações sociais dos grupos dominantes.(VIDAURRI, 2001, p. 29)

Nesse sentido, a partir do entendimento da inviabilidade e da ineficácia de políticas criminais repressivas, 0 desafio da criminologia será produzir transformações sociais e encontrar proposições adequadas para se desviar a nova política criminal de tendência neoliberal que se estabelece.

Por outro lado, outros pesquisadores argumentam que, desde o final do século $X X$, a criminologia tem-se desviado das questões epistemológicas e sociopolíticas, retornando gradativamente à orientação empírica.(SWAANINGEN, 2000, p. 231) Prosseguem, aduzindo que os estudos sobre a subcultura, os vínculos, o controle e a exclusão podem ser realizados por sociólogos, psicólogos, cientistas políticos, antropólogos. Questionam a necessidade da criminologia, ressaltando que esta, quando comparada com outras ciências sociais, destaca-se pelo conhecimento a respeito do sistema de justiça criminal.

Neste momento, a criminologia adota posição acrítica em relação à definição do delito e à reação social, quando, na verdade, esses aspectos são verdadeiramente parte do problema, portanto necessitam ser encarados de forma mais reflexiva.

A necessidade da perspectiva crítica é particularmente importante para o futuro da criminologia, em especial, neste momento em que a ideologia neoliberal conecta o destino da pesquisa criminológica à relevância política. Portanto a consolidação de uma perspectiva crítica é também o desafio para a criminologia.

Nesse compasso, a justiça social é a mais expressiva razão para se estudar a criminologia sob uma perspectiva crítica, especialmente, como crítica à ideologia 
neoliberal. Contudo é preciso adaptar a antiga crítica da justiça social à atual realidade cultural, política e socioeconômica.

\section{POLÍTICA CRIMINAL: A PROCURA DE UMA IDENTIDADE}

Se há dúvidas quanto ao futuro da criminologia, essas também existem quando ao futuro da política criminal. BARATTA salienta que para enfrentar essa questão é preciso centrar nas proposições mais avançadas da criminologia crítica, para tanto se necessita de programas de ação para controlar: "(a) as situações problemáticas e de violação de direitos fundamentais dependentes do comportamento de pessoas físicas; b) os processos de criminalização; c) as conseqüências individuais e sociais das violações de direito e dos processos de criminalização". (1997, p 67)

Complementa ao aduzir que o núcleo do problema da política criminal está no seu objeto uma vez que este se caracteriza pela heterogeneidade e pela indefinição. Para BARATTA, "a construção do objeto e dos instrumentos de controle colocam a política criminal numa crise de identidade e de competência". (1997, p.67)

$\mathrm{Na}$ busca de soluções para essa crise, a sugestão desse autor apóia-se na interdisciplinaridade, concebida como o encontro de diferentes conhecimentos das comunidades científicas, com a proposta de "um encontro de experiências de cientistas e de operadores das diferentes organizações do Estado, de entidades locais e da sociedade civil, para constituir um sujeito coletivo, com comportamentos distintos". (1997, p. 67)

Dessa crise de identidade, conclui-se caminhar a política criminal para adquirir uma dimensão indefinida ou para se conformar num conteúdo penal, especializando-se na produção, na mudança e na implementação de normas de direito penal material, processual e penitenciário, reduzindo-se ao direito penal.

Esses caminhos não são satisfatórios para solucionar o problema de identidade da política criminal tampouco adequados para redimensionar o conceito e o conteúdo nos termos pretendidos neste ensaio.

A partir dessa afirmação, cabe indagar se a política criminal como instrumento de modificação social atingirá sua finalidade, se continuar aprisionada 
no universo do direito penal. Sobretudo é preciso questionar se é possível emancipar a cultura da política criminal da cultura do direito penal.

As proposições político-criminais dos modelos teóricos criminológicos inclinam-se para a superação das políticas criminais de natureza penal, ao reconhecerem ser a política criminal, de base social, capaz de promover transformações sociais no processo de alteração das reais estruturas da sociedade.

Contudo, se no curso do século passado, as instâncias de poder e a sociedade mantiveram-se afastadas das proposições de política criminal produzidas pela criminologia, como, neste momento, promover essa emancipação.

\subsection{A cultura do direito penal}

A criminologia e a política não conseguiram se libertar do ideal de política criminal como instrumento de repressão ao fenômeno criminal. Recorde-se da definição de política criminal de DELMAS-MARTY: "o conjunto dos procedimentos através dos quais o corpo social organiza as respostas ao fenômeno criminal". (1992, p. 24)

A política criminal permaneceu vinculada à imagem de dominação social e de reprovação à criminalidade. Essas funções demandam a violência do Estado por meio do direito penal.

Esteve a política criminal e ainda permanece ligada à cultura do direito penal, como o guardião de bens e valores eleitos pelo corpo social, autorizando-se o legislador (poder público) a tomar decisões, reprimindo todas as condutas.

A política criminal, dessa forma, escravizou-se no caráter repressivo de seu conteúdo, alimentando-se de políticas penais e cultivando o poder preventivo e repressivo do direito penal marcado de um simbolismo incapaz de atender às necessidades demandadas pelo fenômeno criminal. Em torno desse equívoco, a política criminal transformou-se num estéril instrumento de produções legislativas em matéria penal.

O poder político e o imaginário coletivo precisam ser afastados da cultura do direito penal como instrumento único e exclusivo do exercício da política criminal. 
BARATTA sugere que a emancipação da cultura do penal está na "releitura radical de todas as necessidades e de todas as emergências, através do sistema dos direitos fundamentais e da arquitetura normativa da constituição". (1997, p. 68)

Essa releitura parece propor, sobretudo, uma reavaliação dos valores e bens eleitos pelo corpo social para os quais se solicita a proteção do direito penal. $\mathrm{Na}$ verdade, necessita-se semear novos valores, para que germine a tolerância na convivência social.

A partir dessa alteração, a política criminal poderá ser encarada como instrumento de mudança social e de transformação da sociedade, assumindo seu papel criativo e construtor ao comandar e impulsionar essas transformações.

\section{POLÍTICA CRIMINAL: DESAFIO}

O desafio da política criminal para este século é o redimensionamento do seu conceito e do seu conteúdo. O que significa isso? Significa conferir à política criminal um novo contorno, um novo tamanho, um novo valor e uma nova importância.

Por que redimensionar esse conceito? Inadvertidamente, pode surgir uma inclinação para associar esse desafio à demanda por eficiência do controle da criminalidade, da punição do criminoso e das instâncias de controle social. Contudo somente numa visão de política criminal preocupada com a eficiência e o êxito em ter respostas para a criminalidade, dispõe-se lecionar esse engano.

Ao se propor à tarefa de redimensionar novamente a política criminal, buscase sobremaneira identificar contra qual objeto a política criminal deve atuar. Nessa perspectiva, não há dúvidas de que o objeto é a violência. Não só a violência conjuntural (criminal), mas também a violência institucional e a violência estrutural baseadas em uma sociedade excludente, elitista e autoritária.

Num quadro de instabilidade econômica, social e política, a violência pode ser compreendida como estrutural e institucional. A primeira é conseqüência das desigualdades de classe e a segunda, da ausência e da ineficiência na gestão de conflitos pela sociedade e pelo Estado, por meio das instituições formais de controle. (CAPELLER, 1990, p.49) 
Cabe então às opções políticas ter a violência como foco de atuação político-criminal. Desse modo, as propostas político-criminais de conteúdo repressivo e conservador devem ser substituídas por uma política compatível com uma sociedade democrática, protetora dos direitos humanos e fomentadora da ampliação do exercício da cidadania. (DORNELLES, 1997, p.23)

Segundo essa concepção, a política criminal deve abdicar do exclusivo combate ao crime, para se opor à exclusão social com caráter antropológico.

\subsection{Política criminal e Política Penal}

Redefinir o espaço, o valor e a importância é a tarefa da política criminal para atender ao seu objeto de atuação - o tratamento da violência.

A cultura política do direito penal subestima a dimensão da política criminal ao instrumentalizar esta com o direito penal. Por outro lado, a política criminal é capaz de produzir outros e diferentes instrumentos de combate à violência desde que ultrapasse essa cultura. A partir dessa superação, a política criminal conceberá a própria capacidade de enfrentar novos desafios desenvolvendo instrumentos para alcançar o seu objetivo.

Nesse sentido, é imprescindível promover a distinção entre política criminal e política penal, a fim de se reconhecer que esta é apenas um instrumento daquela, sepultando-se, por completo, a concepção de identidade perpetuada no tratamento político da questão.

Para BARATTA, a política penal é entendida "como uma resposta à questão criminal circunscrita ao âmbito do exercício punitivo do Estado" e a política criminal, "em sentido amplo, como política de transformação social e institucional". (2002, p.201)

A importância dessa distinção é destacar a limitação do direito penal no tratamento do problema da violência. Para o tratamento da violência estrutural e institucional, a política criminal não se pode manter aprisionada à cultura do direito penal, mas deve construir "uma política de grandes reformas sociais e institucionais para o desenvolvimento da igualdade, da democracia, de formas de vida comunitária e civil alternativa e mais humanas". (BARATTA, 2002, p. 201) 
Nesse sentido, política criminal deve ser entendida como um sistema coordenado de atos políticos de cunho executivo e legislativo do qual a política penal é apenas um elemento. Esse sistema deve conjugar políticas sociais, democratização e reestruturação das instituições de controle jurídico-penal - polícia, tribunais e prisão, com a finalidade de criar condições básicas para aplicação de políticas penais.

\section{POLÍTICAS CRIMINAIS E COMBATE À VIOLÊNCIA ESTRUTURAL}

A política criminal realizará um salto ao redimensionar seu conteúdo, ultrapassando o objetivo antes centrado na criminalidade para abarcar uma finalidade maior - a violência no âmbito estrutural e institucional.

Entende-se como violência estrutural $o$ ato em que o ser humano perde a sua condição de sujeito de direito. "A violência é, portanto, todo o ato onde o ser humano é tratado sem a sua essência humana, onde perante os outros perde a sua humanidade". (DORNELLES, 1997, p. 105)

Dessa maneira, a violência estrutural pode ser compreendida como o mais desafiador objeto da política criminal numa perspectiva adequada à sociedade democrática, ao respeito aos direitos humanos e à ampliação do exercício da cidadania.

A política criminal precisa concentrar-se no combate a essa violência por meio de ações que influenciem as escolhas econômicas, sociais e políticas dos centros de decisões.É necessário, desse modo, investir em políticas públicas de médio e de longo prazo, com implementação de reformas de caráter social, medidas sócio-educativas, distribuição de renda, ampliação do exercício da cidadania na seara civil, social, econômica e cultural.

BARATTA (1997, p. 69) propõe a releitura da política criminal para construir uma política integral de defesa de direitos. Segundo essa proposta,

a necessidade de segurança da cidadania não é somente uma necessidade de proteção frente à criminalidade e aos processos de criminalização: é uma necessidade de ser e sentir-se garantida em todos os direitos, o de existir, de ser livre, de desenvolver as próprias capacidades; de se expressar e se comunicar, de ter uma qualidade de vida digna e gratificante, de ter voz e poder influir sobre as condições das quais, concretamente, depende a forma própria de ser e existir. 
Ao propor o combate à violência estrutural com políticas públicas de cunho social e político, não se pretende a superação das políticas penais. Ao contrário, propõe-se que a política criminal assegure à política penal espaço autônomo, como parte integrante do sistema, desde que adote uma postura firme de combate à violência de cunho estrutural e institucional.

\subsection{Criminalização de políticas sociais}

O discurso em favor da prevenção à criminalidade por meio de políticas sociais vem sendo proferido pela criminologia, deste os estudos criminológicos da ecologia e da subcultura criminal, pelos centros de poder e pela comunidade.

A premissa teórica dessa prevenção concentra-se no seguinte raciocínio: se o crime tem origem no abismo (social) que separa os indivíduos das classes carentes, das metas, das normas e dos papéis convencionais, devem ser oferecidas alternativas eficazes ao comportamento delitivo pela participação do bem-estar social aos pobres e aos marginalizados. (GARCIA-PABLO, 2000, p. 361)

Por outro lado, o redimensionamento do conteúdo da política criminal professa uma mudança do foco desta que ultrapassa o combate à criminalidade para alcançar a contestação da violência nas suas diversas modalidades. Desta forma, as políticas públicas de cunho social não só devem combater a violência estrutural, mas, sobretudo, precisam garantir direitos aos cidadãos, velando pelos direitos humanos e pelo exercício da cidadania.

A sugestão centra-se na mudança de mentalidade política e social, buscando-se proteger direitos para oportunizar a todas as classes sociais escolhas legítimas de ter voz e poder influir sobre as condições das quais, concretamente, depende a forma própria de ser e de existir.

O diferencial da proposta é que a política criminal desenvolva políticas públicas de cunho social para defender o exercício de garantias e de direitos violados pela violência estrutural, repugnando-se a idéia, até então, professada de prevenção à criminalidade por meio de políticas sociais.

A prevenção à criminalidade por meio de políticas sociais inverte o foco de prioridade, enxergando a violência conjuntural (criminal), como prioridade quando, na verdade, deveria visualizar a garantia de direitos. 
Quando se trabalha com a proposta de políticas sociais para garantia de segurança pública e combate à criminalidade, legitimam-se os processos de exclusão social e moral e, por conseqüência, a violência estrutural é reconhecida como regular.

BARATTA retrata de forma crítica essa inversão. (1997, p. 61)

A ambigüidade ideológica do conceito de política criminal se destaca ainda mais quando o relacionamos a outro aspecto do dilema: a política social. Neste caso se produz uma espécie de compensação[...]. Após negligenciar um número de sujeitos vulneráveis, provenientes de grupos marginalizados ou "perigosos", quando estava em jogo a segurança dos direitos desses grupos, a política criminal os reencontra como "objetos" da política social. Objetos, mas não sujeitos, porque, também desta vez, a finalidade (subjetiva) dos programas de ação não é a de garantir dos seus direitos, mas sim a de defender a segurança das suas vítimas potenciais.

A proposta de combate à violência estrutural por meio de políticas sociais não desconsidera o atual estágio de regressão do Estado Social ao Estado Penal.Em que pese o quadro político indicar o enfraquecimento da proteção social e o fortalecimento do controle penal, o combate à violência estrutural exige a consolidação dos direitos do homem, por meio da construção efetiva de capacidades sociais, como caminho para criação de um Estado efetivamente social. (WACQUANT, 2001, 151)

\section{POLIITICAS CRIMINAIS E VIOLÊNCIA INSTITUCIONAL}

\subsection{Violência Institucional}

O interacionismo simbólico, no estudo do desvio e da criminalidade, focou os processos de definição e de etiquetamento formais e informais, convertendo o estudo das instâncias de controle em objeto da criminologia.O problema central desse estudo é a validade do juízo pelo qual a qualidade de desviante é atribuída a um comportamento ou a um sujeito.

As instâncias de controle institucionais e informais encontram-se no conteúdo da política criminal, quando, ao se redimensionar o objeto de atuação 
desta, identifica-se à violência como objeto e a violência institucional como alvo de ação.

A violência institucional origina-se do sistema de justiça criminal por meio dos instrumentos de controle formal do fenômeno criminal. "A violência institucional é produzida pela ordem social definida pelo direito, ou seja, pela presença do Estado através das instituições de controle jurídico-penal - a polícia, a justiça e a prisão que garantem a vigência da ordem social". (CAPELLER, 1990, p. 49)

Essa violência é valorizada pela ideologia que prega o papel simbólico do Estado, como criador da ordem, dos direitos individuais e sociais que sustentam as relações sociais. Dessa maneira, a violência institucional está relacionada às estratégias de ajustamento sociais e penais propostas pelas instâncias de controle estatal. Essas estratégias podem ser político-jurídicas e político-repressivas. As primeiras relacionam-se com a produção legislativa jurídico-penal, enquanto a segunda, com a atuação repressiva - o policiamento. ${ }^{2}$

A violência institucional, desta forma, está ligada não só ao recrudescimento desproporcional do aparato repressivo do Estado, por meio de propostas legislativas e executivas, mas também ao funcionamento desse aparato.

\subsection{Violência institucional na produção das normas penais}

As estratégias jurídico-penais que evidenciam a violência institucional são observadas nas propostas de penas capitais, de redução da idade de responsabilidade penal e de criminalização de novas condutas. Por sua vez, as estratégias político-repressivas, na militarização da segurança pública e na tolerância de práticas ilegais, violentas, seletivas e estigmatizantes das instâncias formais de controle.

É preciso colocar em evidência que o combate às ações transgressoras desviantes constitui uma das mais violentas práticas de um ampliado e complexo controle social de dominação política. A partir dessa constatação, a violência na produção da criminalização primária e da criminalização secundária precisa estar no

${ }^{2}$ O termo policiamento é utilizado para identificar a atuação dos órgãos formais de controle - Polícia, Ministério Público, Judiciário. 
campo de combate da política criminal voltada à garantia de direitos fundamentais e ao exercício da cidadania.

BARATTA (1997, p. 61) sugere um controle do sistema de justiça criminal, propondo o controle interno como controle formal e jurídico com base nos princípios da igualdade, liberdade e legalidade e, por outro lado, o controle externo como controle político e de justiça material relativo à seleção e à defesa dos bens jurídicos, questionando-se a relação entre benefícios e custos sociais da intervenção.

Uma proposta de política criminal oposta à violência institucional deve centrar-se na democratização do sistema de justiça criminal representado pelas diversas instâncias: legislativa, dogmática, jurisprudencial e policial.

Democratizar a criminalização primária deve estar no foco da política criminal que pretende ser instrumento de transformação social. Não se pode pensar a criminalização primária sem considerar os interesses e as opiniões dos diferentes sujeitos sociais: comunidades, formas associativas e sociedade civil e sem incorporar a sociedade civil na formulação de políticas penais.

A sociedade está alijada do processo de criminalização primária, o que provoca uma despolitização e uma dessocialização do problema criminal.

É importante destacar que essa afirmação não se descaracteriza diante de demandas sociais por medidas legislativas de caráter repressivo, marcadas pelo casuísmo e pelo apelo emocional de uma elite despreparada politicamente, conservadora e protetora de uma estrutura social segregante e de uma ordem social desigual e injusta.

A participação política da sociedade na elaboração legislativa jurídico-penal que se pretende é aquela capaz de expressar as necessidades dos diversos sujeitos sociais envolvidos com o problema criminal, por meio do processo de interação entre as ciências sociais, ciências políticas, criminologia, centros de decisões e sociedade.

As instâncias formais de controle mostram-se rigorosas quando a sociedade tende a ser mais tolerante. Talvez neste ponto encontra-se o desafio das políticas criminais de controle da violência institucional na esfera legislativa - edificar uma consciência legislativa mais tolerante em relação aos diversos modos de viver em comunidade. 


\subsection{Violência institucional e aplicação das normas penais}

A criminologia interacionista revelou não apenas o processo de seleção da delinqüência, mas também a regularidade das cifras ocultas, traduzidas pelo predomínio desproporcionado das classes inferiores nas instâncias de controle e nas estatísticas oficiais da criminalidade. (DIAS, 1984, p. 385)

Nesse sentido, a ação das instâncias de controle formal é diferencialmente distribuída entre os diversos estratos sociais. A_discricionariedade real das instâncias formais de controle é representada por mecanismos de seleção, responsáveis pela desproporcional presença dos desfavorecidos nas estatísticas oficiais da delinqüência. Dessa forma, o controle social pelas instâncias formais do sistema de justiça criminal é marcado não só pela desigualdade no tratamento do delito, mas também pela tolerância no controle da legalidade do próprio sistema.

Como parte da sociedade, o sistema de justiça criminal é funcional a esta, ao reproduzir a exclusão, a injustiça social e a violência contra os segmentos mais pobres da população.

A atuação desse sistema cumpre o papel esperado pelas elites, nas sociedades em que o conceito de segurança não significa segurança e bem-estar do público, mas ao contrário, expressa a manutenção de uma ordem social desigual e injusta. (DORNELLES, 1997, p. 113)

A violência institucional desse sistema exterioriza-se pela seleção de indivíduos pertencentes aos estratos sociais mais baixos e pela direção de atuação a determinadas condutas sociais. O sistema é violento ao eleger quem serão os sujeitos da atuação dele e ao determinar contra quais condutas recairá a ação.

Nesse compasso, a política criminal, para promover a transformação social, precisa combater a violência institucional tanto por meio da democratização quanto pela reestruturação do sistema, para que represente a sociedade e não apenas uma parte desta.

\subsection{Reestruturação do sistema de justiça criminal}

"A nota mais saliente do sistema de reação ao crime na sociedade contemporânea é a sua profissionalização e burocratização". (DIAS, 1984, p. 374) 
O marco atual desse sistema é a impessoalidade de indivíduos investidos em papéis e integrados em carreiras ocupacionais, perseguindo o sucesso profissional. Nesse contexto, as decisões são determinadas pelo sentido normativo das leis e sobretudo pelas ideologias interiorizadas por esses indivíduos.

Os agentes de controle formal encontram-se em posições bem distintas dos sujeitos ao controle. Aqueles cumprem uma rotina profissional, sem qualquer interação com os controlados e com o meio social destes, produzindo uma atuação afastada daqueles para os quais o controle se dirige. Circunstância que se agrava pelo formalismo dos procedimentos legais.

As estruturas do sistema penal, por essas razões, perdem o caráter institucional e se personalizam, passando a perseguir valores e projetos pessoais na administração do problema criminal quando deveriam buscar projetos institucionais e sociais na proteção de valores coletivos. Com isso as estruturas do sistema formal de controle do crime mostram-se descomprometidas com a realização da justiça social.

Por outro lado, o sistema penal não contém um conjunto organizado de estruturas, ao contrário, as diversas estruturas que compõem esse sistema não se interagem. A política criminal, ao perseguir a violência institucional, deve promover reformas estruturais e organizacionais no sistema de justiça criminal, buscando a democratização desse sistema.

A título meramente exemplificativo podem-se citar as seguintes propostas: a transparência das estruturas do sistema penal; a integração entre as diversas estruturas; controle externo dessas estruturas; implementação da comunicação entre as estruturas e entre estas e os sujeitos sociais; informalização das estruturas e dos procedimentos.

A democratização do sistema de justiça criminal busca a igualdade que, embora expressa pelo Estado de Direito, não se realiza. Essa igualdade externa-se como mero "enunciado duma igualdade expressa em direitos processuais cuja consistência é, na prática, intoleravelmente desigual”. (DIAS, 1984, p. 395) 


\section{POLÍTICA CRIMINAL E VIOLÊNCIA CONJUNTURAL (CRIMINAL)}

\subsection{O papel do direito penal}

A função punitiva é encontrada nos mais remotos momentos da vida em sociedade. Pode-se mencionar que as primeiras manifestações jurídicas ocorreram no campo do direito penal em razão do caráter punitivo e organizacional deste. $\mathrm{O}$ direito penal existiu primeiramente como sanção, para depois como disciplina das complexas relações que se estabelecem na sociedade, entre os próprios homens e entre estes e o Estado.

A partir dessa idéia, o direito penal assumiu a função de proteção dos bens jurídicos diante de possíveis lesões ou perigo (TOLEDO, 1994, p. 13). Em outro sentido, para ZAFFARONI, o objeto do direito penal é a regulamentação de conduta humana por meio de cominações.(1999, p. 85)

Pode-se afirmar que, na tradição majoritário, o direito penal tem por meta a segurança jurídica e a defesa social.Nesse contexto, é difícil aduzir qual a função que o direito penal cumpre efetivamente na sociedade, uma vez que a função real não coincide com a função declarada.

A criminologia e a sociologia destacam essas diferenças. Para a criminologia crítica, o sistema penal, por meio do direito penal, cumpre a função de selecionar, arbitrariamente, pessoas dos setores sociais desprestigiados, criminalizando-as para limitar o espaço social.

Exerce o direito penal, dessa forma, uma função simbólica de assegurar a hegemonia de um setor social. É preciso negar então a tarefa eminentemente jurídica dada ao direito penal para conferir a este um caráter político. Contesta-se, dessa forma, a concepção de que o objetivo do direito penal se concretiza pela formalização positiva, por meio da edição legislativa.

O direito penal precisa transforma-se buscando a superação do distanciamento do discurso jurídico e da realidade concreta. Extrai-se dessa afirmação que o direito penal necessita reavaliar, assim como a criminologia e a política criminal, o seu conteúdo - o conhecimento jurídico penal.

Esse debate está em plena marcha e, nesse percurso, transitam posições ideológicas conservadoras e críticas. No entanto, dentre as diversas correntes 
possíveis, merece destaque a necessidade de uma crítica permanente do direito penal, confrontando-o com a aptidão para realizar os direitos fundamentais e ampliar o exercício da cidadania.

O direito penal deve-se transformar em instrumento de integração e não de marginalização, vinculado com os direitos humanos, portanto comprometido ideologicamente com o aumento do espaço social de todos os membros da sociedade, por meio de soluções concretas para trabalhar as questões da violência conjuntural, em conjunto com os problemas da violência institucional e estrutural. (ZAFFARONI, 2001, p. 82)

\subsection{Contornos constitucionais da política penal}

Na preservação de direitos fundamentais, as políticas penais devem assumir contornos constitucionais. Neste momento, é necessária a releitura da afirmação de VAN LIZST segundo a qual o "direito penal é a barreira intransponível de toda política criminal". (citado por GARCIA-PABLOS, 2000, p. 153). Talvez se deva reconstruir esta afirmação no sentido de colocar o direito constitucional, na expressão dos direitos fundamentais, como a barreira intransponível de toda a política criminal e, em especial, da política penal.

O estatuto político do Estado é a primeira manifestação legal de política penal, uma vez que reflete o processo de decisão política formadora de um determinado perfil do Estado. Por essa razão, o modelo de direito penal deve se sujeitar diretamente às escolhas tomadas ao traçar o perfil estatal. (LOPES, 1997, p. 44)

Nesse processo, definiram-se os princípios políticos constitucionais que estruturam o Estado, como, por exemplo, o princípio democrático, o princípio da separação e interdependência dos poderes, o princípio do pluralismo e as competências e as atribuições dos órgão políticos. Sobretudo se determinam os princípios, as formas e os processos fundamentais da formação da vontade política e das decisões por parte do poder político.

Nesse contexto, a Constituição determina os princípios que devem nortear as decisões de política criminal do Estado, buscando-se a aproximação dos valores constitucionais com o direito penal, por meio da política penal. 
As normas constitucionais, dessa forma, constituem o padrão de validade das normas penais, determinando o sentido que o legislador penal deve seguir na qualificação das ações delituosas e no estabelecimento das respectivas penas.

O sistema penal precisa estar em harmonia com os valores positivados pela Constituição a qual exige uma evolução do direito penal, e conseqüentemente, das políticas penais.

Nesse compasso, as políticas penais devem caminhar para um direito penal voltado para a tolerância e para a liberdade, inaugurando um processo de descriminalização com base nos valores e princípios eleitos pela Constituição que, ao propor um Estado Democrático de Direito, destacou a importância da dignidade da pessoa humana e a prevalência dos direitos humanos.

Os princípios constitucionais devem ser os instrumentos de política penal para a transformação do direito penal em meio de integração e não de marginalização. A política penal deve reconstruir o direito penal apoiando-se nos princípios constitucionais de preservação da dignidade humana e da proteção aos direitos humanos. Nesses sentido, o direito penal pode-se tornar mecanismo legítimo de controle da violência conjuntural.

\subsubsection{Política penal desenhada pelos princípios constitucionais}

Os princípios constitucionais precisam ser valorizados na edificação de um sistema de direito penal - direito constitucional penal. Não só se prega a aplicação de princípios básicos de direito penal, como a legalidade, mas também a valorização de princípios estruturais de conteúdo ideológico e filosófico, como os da dignidade humana, dos direitos humanos e da busca do bem comum.

Lamentavelmente, no Brasil, os princípios constitucionais de natureza processual foram colocados em posição de prioridade em relação aos princípios constitucionais de natureza material.

Dessa forma, a importância da conformação constitucional nas diretrizes orientadoras do direito penal foi desconsiderada até que, superando-se a mera orientação relacionada à aplicação da pena, os princípios constitucionais de direito penal adquiriram relevância quanto à elaboração das figuras penais - princípio da legalidade e princípio da anterioridade. 
A partir desses princípios, devem-se extrair outros princípios constitucionais de direito penal ainda que implícitos no texto. Segundo LOPES (1997, p. 68) podese considerar "os seguintes princípios do Direito Penal quanto ao preceito primário: legalidade, intervenção mínima, insignificância, taxatividade, lesividade, culpabilidade e humanidade. Quanto ao preceito secudário [...] os princípios da proporcionalidade, individualização e finalidade da penal".

Política criminal não mais encontra barreira no direito penal, mas no direito constitucional que determina estar o direito penal condicionado aos valores e aos princípios daquele. As normas penais devem estar em harmonia com os princípios constitucionais da intervenção mínima e da humanidade, para que tenham legitimidade, validade no mundo jurídico.

Por outro lado, os valores e princípios constitucionais devem pautar a ação do sistema de justiça criminal que precisa superar a mentalidade da defesa social e assumir o papel de transformador social - focando os direitos fundamentais como pilar de ação.

\section{CONCLUSÃO}

Propõe-se, então, a concretização da política criminal como política de transformação social a partir da aproximação com o exercício do poder. Como instrumento de construção política, este pode conferir novos contornos e nova potencialidade à política criminal.

Ao se alcançar essa potencialidade, deve a política criminal encontrar um novo foco de atuação. Este é a violência, concebida em sentido amplo como violência estrutural, institucional e conjuntural (criminal).

Dessa maneira, acredita-se que, somente a partir da superação do tradicional objeto da política criminal - o combate à criminalidade - e da adoção de novos desafios - o combate à violência - poderá a política criminal assumir seu papel político de transformação social, realizando a transformação de homens em cidadãos. 


\section{REFERÊNCIAS}

BARATTA, Alessandro. Defesa dos Direitos Humanos e Política Criminal. Discursos sediciosos, Rio de Janeiro, Cortesia, n. 3, p. 57-69, 1을 semestre 1997.

BARATTA, Alessandro. Criminologia Crítica e Crítica do Direito Penal. Rio de Janeiro: Revan: Instituto Carioca de Criminologia, 2002.

CAPELLER, Wanda de Lemos. Violência e políticas criminais de ajustamento social. Fascículos de Ciências Penais, Porto Alegre n. 4. p.39-55, out./dez. 1990.

DIAS, Jorge de Figueiredo; ANDRADE, da Costa Manoel. O homem delinqüente e a sociedade criminológica. Coimbra: Limitada, 1984.

DELMAS-MARTY, Mireille. Modelo e movimentos de política criminal. Rio de Janeiro: Revan, 1992.

DORNELLES, João Ricardo Wanderley. Violência urbana, direitos da cidadania e políticas públicas de segurança no contexto de consolidação das instituições democráticas e das reformas econômicas neoliberais. Discursos sediciosos, Rio de Janeiro, Cortesia, n. 4, p. 103-120, 1997.

GARCÍA- PABLOS, Antonio de Molina. Criminologia. 3. ed. São Paulo: Revista dos Tribunais, 2000.

LOPES, Maurício Antonio Ribeiro. Direito penal, estado e constituição: princípios constitucionais politicamente conformadores do Direito Penal. São Paulo: IBCCRIM, 1997.

SWAANINGEN, René Van. Reinvindicando a la criminologia crítica: Justiça social y Tradición Europea. Revista Brasileira de Ciências Criminais. São Paulo: IBCCRIM, ano 08, número 32, outubrodezembro 2000.

TOLEDO, Francisco de Assis. Princípios básicos de Direito Penal. 5. ed. São Paulo: Saraiva, 1994.

VINDAURRI, Alicia González. Globalización, post modernidad y política criminal. Revista Brasileira de Ciências Criminais. São Paulo: IBCCRIM, ano 09, número 36, outubro-dezembro 2001.

WACQUANT, Loïc, As prisões da miséria. Rio de Janeiro: Jorge Zahar, 2001.

ZAFFARONI, Eugenio Raúl. Manual de Direito Penal Brasileiro: Parte Geral. 3ed. São Paulo: Revista dos Tribunais, 2001. 